\title{
Epithelial c-jun and c-fos are temporally and spatially regulated by estradiol during neonatal rat oviduct differentiation
}

\author{
Akinobu Okada ${ }^{1,2}$, Yasuhiko Ohta ${ }^{2,5}$, Steven L Brody ${ }^{3}$ and \\ Taisen Iguchi ${ }^{4,5}$ \\ ${ }^{1}$ Safety Research Laboratories, Yamanouchi Pharmaceutical Co., Ltd., Tokyo 174-8511, Japan \\ ${ }^{2}$ Department of Veterinary Science, Faculty of Agriculture, Tottori University, Tottori 680-8553, Japan \\ ${ }^{3}$ Department of Internal Medicine, Washington University School of Medicine, St Louis, MO 63110-1093, USA \\ ${ }^{4}$ Center for Integrative Bioscience, Okazaki National Research Institutes, and Department of Molecular Biomechanics, School of Life Science, The Graduate \\ University for Advanced Studies, Okazaki 444-8585, Japan \\ ${ }^{5}$ CREST, Japan Science and Technology, Kawaguchi 332-0012, Japan \\ (Requests for offprints should be addressed to T Iguchi; Email: taisen@nibb.ac.jp)
}

\begin{abstract}
Expression of transcription factors binding to the activating protein-1 (AP-1) site is induced by estrogens in association with epithelial proliferation in the uterus, but, in the oviduct, the relationship between cell proliferation and differentiation and AP-1 transcription factors is not well understood. In the developing rat oviduct, we found that proliferation and differentiation of epithelial cells were region-dependently regulated by $17 \beta$-estradiol (E2). To determine the role of AP-1 transcription factors in the development of rat oviduct, we performed immunohistochemistry for epithelial c-jun and c-fos proteins in E2-untreated and -treated newborn rats. E2 increased the expression of c-jun and c-fos during proliferation
\end{abstract}

of undifferentiated epithelial cells, but diminished both proteins during accelerated differentiation of ciliated epithelial cells. A pure estrogen receptor (ER) antagonist, ICI 182,780 , inhibited changes in their expression during both cell proliferation and differentiation. Importantly, no reduction of c-jun was noted in the epithelial cells of the foxj1-deficient oviduct, which lacks cilia development. This study shows that c-jun and c-fos are regulated during epithelial cell proliferation and differentiation in a regionspecific manner. This provides critical information for understanding the molecular and cellular mechanisms of the development of the neonatal oviduct.

Journal of Endocrinology (2004) 182, 219-227

\section{Introduction}

The development of the female reproductive tract is highly dependent on estrogens that act via estrogen receptors $\alpha(\operatorname{ER} \alpha)$ and $\beta(\operatorname{ER} \beta)$, which are members of ligand-inducible nuclear transcription factor receptors (Mangelsdorf et al. 1995). The estrogen and ER complex generate either a homo- or hetero-dimer that binds to the estrogen response element (ERE) sequence on target DNA and can activate transcription of various functional downstream genes. Proto-oncogenes proteins such as c-jun and c-fos are nuclear transcription factors whose homo- or hetero-dimer complex bind to the activating protein-1 (AP-1) site and regulate the cell proliferation, differentiation, and transformation (Angel \& Karin 1991). It has been well documented that the estrogens can regulate the expression of AP-1 transcription factors including c-jun and c-fos by interacting with their functional ERE (Rauscher et al. 1988, Weisz \& Rosales 1990, Hyder et al. 1992, 1995, Schuchard et al. 1993, Weisz \& Bresciani 1993). During a normal estrous cycle, the expression of c-fos is regulated in association with cell proliferation, plasma estradiol (E2), and ER $\alpha$ expression in the rat luminal epithelium (Mendoza-Rodrí guez et al. 2003). It is well known that the uterine epithelial cells proliferate due to E2, and that the transcription of $\mathrm{c}$-jun and c-fos genes is rapidly and dramatically induced in the uteri of ovariectomized immature and mature rats and mice treated with E2 or diethylstilbestrol (DES), a synthetic estrogen (Loose-Mitchell et al. 1988, Weisz \& Bresciani 1988, Weisz et al. 1990, Webb et al. 1990, 1993, Chiappetta et al. 1992, Kamiya et al. 1996). The estrogeninduced expressions of c-jun and c-fos are not prevented by protein synthesis inhibitors, suggesting a primary response to the ER complex. It was demonstrated, despite an increase in c-fos expression after E2 treatment, that E2 reduced c-jun expression in the uterine epithelial cells of immature and adult ovariectomized rodents neonatally treated or untreated with DES (Bigsby \& Li 1994, Yamashita et al. 2001, 2003). Taken together, although there is a discrepancy in the reporting of c-jun changes, these findings suggest that $c-j u n$ and $c$-fos play critical 
roles in regulating E2-dependent cell proliferation in the uterine epithelium.

Several experimental models on the neonatal oviduct have shown that epithelial cell proliferation is regulated by E2, as in the uterus (Jansen 1984). Perinatal exposure to DES induced cell proliferation and caused abnormal morphology in mouse and rat oviducts (Newbold et al. 1983, Okada et al. 2001). Also, in immature chicks, E2 induced cell proliferation in the oviductal epithelium (Anderson \& Hein 1976). However, unlike in the uterus, the effects of E2 on the expression of AP-1 transcription factors have not been reported in the mammalian oviduct, but only in the immature chick oviduct whose c-jun and c-fos were rather reduced, with increased ovalbumin production, after E2 treatment (Cohrs et al. 1988, Lau et al. 1990). It is possible that the discrepancy in AP-1 transcription factor expression between the uterus and the oviduct is related to unique epithelial cells specific to the developing oviduct (Weisz \& Bresciani 1993). However, this hypothesis has not been well demonstrated since previous chick studies were conducted by using a homogenate of the whole oviduct.

The oviduct has more complex morphological features than the uterus, which contains only a single epithelial cell type and lacks regional differences. Within the oviductal lumen, there is regional distribution of at least two types of epithelial cells, ciliated and secretory cells. In addition to cell proliferation, E2 regulates the differentiation of epithelial cells in the oviduct. The appearance of immunoreactivity for $\beta$-tubulin IV, an epithelial cilia marker protein (Renthal et al. 1993), occurred on the 7th day after birth (ND 7) and was accelerated by treatment with E2 in neonatal mouse and rat oviducts (Eroschenko 1982, Abe \& Oikawa 1993). $\beta$-tubulin IV-positive epithelial cells appeared in the ND 5 rat oviduct after E2 treatment for 5 days (Okada et al. 2004). Differentiation of secretory cells was also induced by E2 treatment in the hamster oviduct (Abe \& Oikawa 1993). Moreover, we recently reported that cell proliferation and differentiation of epithelial cells were region-dependently induced at the isthmus/ uterotubal junction (IST/UTJ) and infundibulum/ ampulla (INF/AMP), respectively, in the neonatal rat oviduct treated with E2 for 5 postnatal days (Okada et al. 2004). We put forward a hypothesis, therefore, that in the neonatal rat oviduct, c-jun and c-fos are expressed regionand cell type-dependently, which were regulated by E2 in association with cell proliferation and differentiation. To demonstrate the detailed expression of epithelial c-jun and c-fos during the neonatal development of the oviduct, immunohistochemical evaluations of protein expression was performed in each region of the neonatal rat oviduct treated with or without E2 for 5 days from the day of birth. We show that c-jun and c-fos regulate region-dependent epithelial cell differentiation during neonatal oviduct development, suggesting that AP-1 transcription factors direct epithelial proliferation and differentiation of the oviduct in response to E2.

\section{Materials and Methods}

Animals and treatments

Animals were maintained in accordance with the NIH and the Institutional Guides for the Care and Use of Laboratory Animals. Male and female Sprague-Dawley rats were obtained from Charles River Japan, Inc. (Kanagawa, Japan). Animals were housed individually in stainless-steel cages with controlled temperature $\left(23 \pm 2{ }^{\circ} \mathrm{C}\right)$ and relative humidity $(55 \pm 10 \%)$, and a 13 -h light/11-h dark cycle (8:00-21:00). Pellet food (CRF-1, Oriental Yeast Co., Ltd, Tokyo, Japan) and municipal tap water were freely available. Females (15 weeks of age) were cohabited overnight with males for impregnation. The day on which neonates were born was designated as ND 0. In rat studies, oviducts were removed from untreated neonatal rats on ND 0, 3, 5, 7 and 10. Foxj1-deficient mice (Brody et al. 2000), and their wild-type littermates were used at 3 weeks of age.

To investigate the effect of E2, 16 to 24 female neonates in each group were injected subcutaneously daily with either sesame oil or $10 \mu \mathrm{g}$ of E2 (Sigma, St Louis, MO) for 5 days (ND 0 to 4). Similarly, sesame oil or $10 \mu \mathrm{g}$ of ICI 182,780 (Tocris Cookson, Inc., Ballwin, MO) was concomitantly injected for 5 days (ND 0 to 4 ). Oviducts were removed $24 \mathrm{~h}$ after the last injection (ND 5), and immediately prepared for immunohistochemistry. E2 and ICI were dissolved in sesame oil and injected at $0.05 \mathrm{~mL}$ per neonate.

\section{Antibodies}

Mouse monoclonal antibodies against proliferating cell nuclear antigen (PCNA) (PC10; Dako Corporation, Carpinteria, CA) and $\beta$-tubulin IV (ONS1A6; BioGenex, San Ramon, CA) were used at a dilution of $1: 100$ and 1:250, respectively. A mouse monoclonal antibody against oviductal glycoprotein (OGP), which recognizes proteins with more than $330 \mathrm{kDa}$ of OGP, was purchased from the Institute for Functional Peptide (C8B11; Yamagata, Japan). The binding specificity of these antibodies has been previously established (Bannerjee et al. 1992, Abe \& Abe 1993). Rabbit polyclonal antibodies against c-jun (H-79) and c-fos (K-25) were obtained from Santa Cruz Biotechnology, Inc. (Santa Cruz, CA), and used at a dilution of 1:100. According to the data sheet provided by the manufacturer, the c-jun antibody reacts with c-jun, but not jun $\mathrm{B}$ or jun $\mathrm{D}$, while the c-fos antibody reacts with fos $\mathrm{B}$, fra- 1 , and fra- 2 in addition to $\mathrm{c}-\mathrm{fos}$.

\section{Tissue preparation and immunohistochemistry}

Neonatal oviducts were fixed with $4 \%$ paraformaldehyde in $0.1 \mathrm{M}$ phosphate buffer overnight at $4{ }^{\circ} \mathrm{C}$. Paraffinembedded samples cut in $4 \mu \mathrm{m}$ serial sections were 
Table 1 Immunoexpression of epithelial PCNA, c-jun and c-fos in the neonatal rat oviduct

\begin{tabular}{|c|c|c|c|c|c|c|c|}
\hline & \multirow[b]{2}{*}{ ND 0} & \multirow[b]{2}{*}{ ND 5} & \multirow[b]{2}{*}{ ND 7} & \multicolumn{2}{|l|}{ ND 10} & \multicolumn{2}{|l|}{$E 5^{b}$} \\
\hline & & & & $\mathrm{INF} / \mathrm{AMP}$ & IST/UTJ & INF/AMP & IST/UTJ \\
\hline $\mathrm{PCNA}^{\mathrm{a}}$ & $8 \cdot 8 \pm 5 \cdot 66$ & $23 \cdot 9 \pm 4 \cdot 04$ & $18 \cdot 9 \pm 7 \cdot 02$ & $9 \cdot 5 \pm 3 \cdot 21$ & $32 \cdot 9 \pm 6 \cdot 13$ & $18 \cdot 6 \pm 3 \cdot 31^{*}$ & $36 \cdot 0 \pm 7 \cdot 51^{*}$ \\
\hline c-Jun & +++ & +++ & ++ & + & ++ & + & +++ \\
\hline c-Fos & +++ & ++ & \pm & \pm & + & - & ++ \\
\hline
\end{tabular}

ND, neonatal day; INF/AMP, infundibulum/ampulla; IST/UTJ, isthmus/uterotubal junction.

+++ , marked; ++ , moderate; + , weak; \pm , slight; - , negative.

apercentage of PCNA-positive cells in the epithelium.

${ }^{b}$ E2-treated ND 5 oviduct.

${ }^{*} P<0 \cdot 05$ vs oil-treated ND $5(24 \cdot 2 \pm 6 \cdot 19)$.

deparaffinized, rehydrated, and autoclaved at $121{ }^{\circ} \mathrm{C}$ for $15 \mathrm{~min}$ in $10 \mathrm{mM}$ citrate buffer $(\mathrm{pH} 6.0)$, for antigen retrieval. Sections were then rinsed in distilled water and incubated with $0 \cdot 3 \%$ hydrogen peroxide for $30 \mathrm{~min}$. After rinsing with PBS, sections were treated with normal sheep serum (Dako Corporation, Carpinteria, CA) for $30 \mathrm{~min}$, and then incubated for $30 \mathrm{~min}$ with anti-PCNA antibody, for $2 \mathrm{~h}$ with anti-OGP antibody, or for $16 \mathrm{~h}$ at $4{ }^{\circ} \mathrm{C}$ with anti-c-jun or c-fos antibody. Sections were rinsed in PBS and treated with Simple Stain Rat MAX-PO (Nichirei, Tokyo, Japan) for $30 \mathrm{~min}$. After a final PBS wash, sections were treated with $0 \cdot 01 \%$ 3,3'-diaminobenzidine tetrahydrochloride (Dojindo Laboratories, Kumamoto, Japan) in $0.05 \mathrm{M}$ Tris- $\mathrm{HCl}$ at $\mathrm{pH} 7 \cdot 6$ containing $0 \cdot 068 \%$ imidazole (Sigma) and $0 \cdot 02 \%$ hydrogen peroxide for $5 \mathrm{~min}$.

For double immunohistochemistry, sections stained for PCNA, c-jun, or c-fos as described above were rinsed in PBS and blocked in normal sheep serum, followed by incubation with the anti- $\beta$-tubulin IV antibody overnight at $4{ }^{\circ} \mathrm{C}$. Sections were rinsed in PBS and treated with EnVision/AP (Dako) for $30 \mathrm{~min}$. After rinsing in PBT, they were treated with Fuchsin (Dako) containing levamisole (Dako) for $5 \mathrm{~min}$.

All sections were lightly counter-stained with hematoxylin (Dako A/S, Glostrup, Denmark). Normal mouse IgG and normal rabbit immunoglobulin fraction (both Dako A/S) were used as negative controls in place of primary antibodies for PCNA, $\beta$-tubulin IV and OGP, and c-jun and c-fos stainings, respectively. In addition, for c-fos immunostaining, sections were also incubated with the anti-c-fos antibody that had been pre-absorbed with c-fos peptide (Santa Cruz) overnight at $4{ }^{\circ} \mathrm{C}$. Negative controls showed no specific immunoreactivity in all experiments. Sections were examined and photographed using a lightmicroscope attached to a digital CCD camera (BX60 and DP50, Olympus Optical Co., Ltd, Tokyo, Japan).

\section{Evaluation and statistical analysis}

For c-jun and c-fos immunohistochemistry, at least seven specimens from each of five animals were examined, and staining intensity was graded as negative, slight, weak, moderate, or marked. Epithelial cell proliferation was calculated as a percentage of the PCNA-labeled cells in all epithelial cells in each section evaluated. At least five specimens from each of five animals were examined.

Statistical analysis was carried out, using Duncan's multiple comparison test, for the effects of E2 on PCNA expressions. Data are represented as mean $\pm \mathrm{SD}$ and considered significantly different at $P<0 \cdot 05$.

\section{Results}

Epithelial proliferation and differentiation in the untreated-neonatal rat oviduct

To understand the neonatal development of the oviduct, we first evaluated ontogenic proliferation and differentiation of epithelial cells in untreated-neonatal rats. The neonatal oviduct was a simple tube structure from ND 0 to ND 7, and subsequently differentiates morphologically into the INF/AMP and the IST/UTJ. Proliferating epithelial cells were determined by the immunohistochemical detection of PCNA (Table 1 and Fig. 1). Epithelial PCNA was expressed in a few cells on ND $0(8 \cdot 8 \%)$, and was expressed in more cells on ND $5(23.9 \%$, Fig. 1A). A decrease in PCNA-expressing cells occurred on ND 7 (18.9\%, Fig. 1B) and ND 10 at the INF/AMP region (9.5\%, Fig. 1C). At the IST/UTJ, however, many epithelial cells expressing PCNA were still observed on ND $10(32.9 \%$, Fig. 1D). It is evident, then that there are temporal and spatial differences in cell proliferation within the oviduct lumen.

The expression of cilia protein $\beta$-tubulin IV and oviductal secretory protein OGP was used as a marker of differentiated ciliated and secretory epithelial cells, respectively, and evaluated by immunohistochemistry during neonatal oviduct development. No expression of epithelial $\beta$-tubulin IV was detected in the oviduct from ND 0 to 5 (Fig. 2A). $\beta$-tubulin IV appeared on the luminal surface of some epithelial cells on ND 7 (Fig. 2B). After morphological differentiation of the oviduct into different regions, the number of epithelial cells expressing 

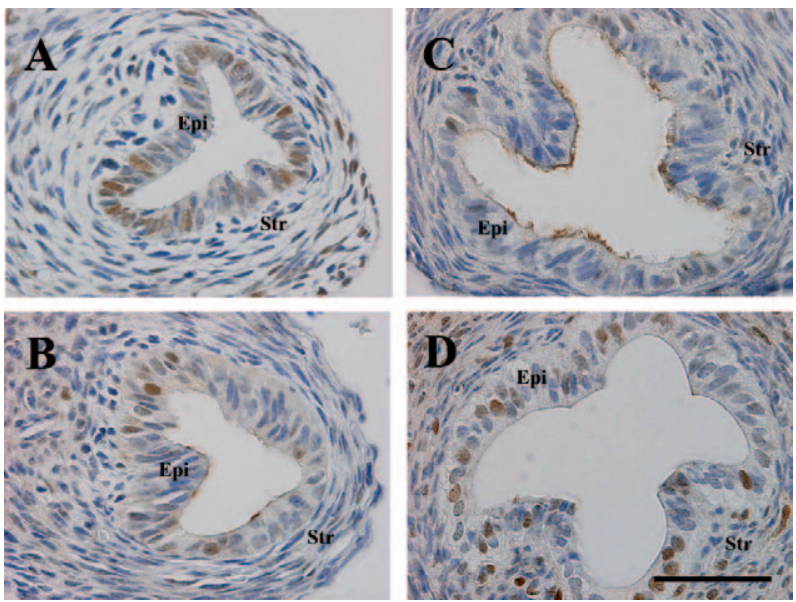

Figure 1 Cell proliferation of epithelial cells in the untreated neonatal rat oviduct. Proliferating cells were determined by immunohistochemistry for PCNA. PCNA-expressing epithelial cells were detected on ND $5(A)$, but their number decreased on ND 7 (B). On ND 10, fewer cells in the INF/AMP expressed PCNA (C), while more cells in the IST/UTJ did (D). Epi, epithelium; Str, stroma. Bar: $50 \mu \mathrm{m}$.

$\beta$-tubulin IV increased and were numerous in the INF/ AMP on ND 10 (Fig. 2C). In contrast, no epithelial $\beta$-tubulin IV-positive cells were found in the IST/UTJ by ND 10 (Fig. 2D). The expression of OGP was absent from all epithelial cells on ND 0 to 5 (Fig. 2E), and detected in the cytoplasm of some epithelial cells on ND 7 (Fig. 2F). Epithelial cells positive for OGP increased on ND 10 at the IST/UTJ (Fig. 2H) and, however, they did not appear at the INF/AMP region (Fig. 2G). Thus, regional differentiation into ciliated or secretory epithelial cells in the rat oviduct occurred after ND 5, following active epithelial proliferation.

Ontogeny of epithelial c-jun and c-fos proteins in the untreated-neonatal rat oviduct

To determine if AP-1 proteins regulate regional oviduct differentiation, we determined the expression pattern of c-jun and c-fos during oviduct development (Table 1). All epithelial cells showed c-jun and c-fos nuclear expression at a marked level on ND 0 (Table 1), but on NDs 5 and 7, it decreased to a moderate or slight level (Figs. 3A, 3B, $3 \mathrm{E}$, and $3 \mathrm{~F}$ ). In the INF/AMP on ND 10, epithelial c-jun and c-fos decreased (Figs. 3C and 3G), however, in the IST/UTJ, moderate or weak expressions were maintained until ND 10 (Figs. 3D and 3H). Therefore, although the correlation between $\beta$-tubulin IV- and AP-1 proteinpositive cells was not established in this study, epithelial c-jun and c-fos in the INF/AMP decreased in correlation with reduced cell proliferation and the subsequent differentiation of ciliated cells.
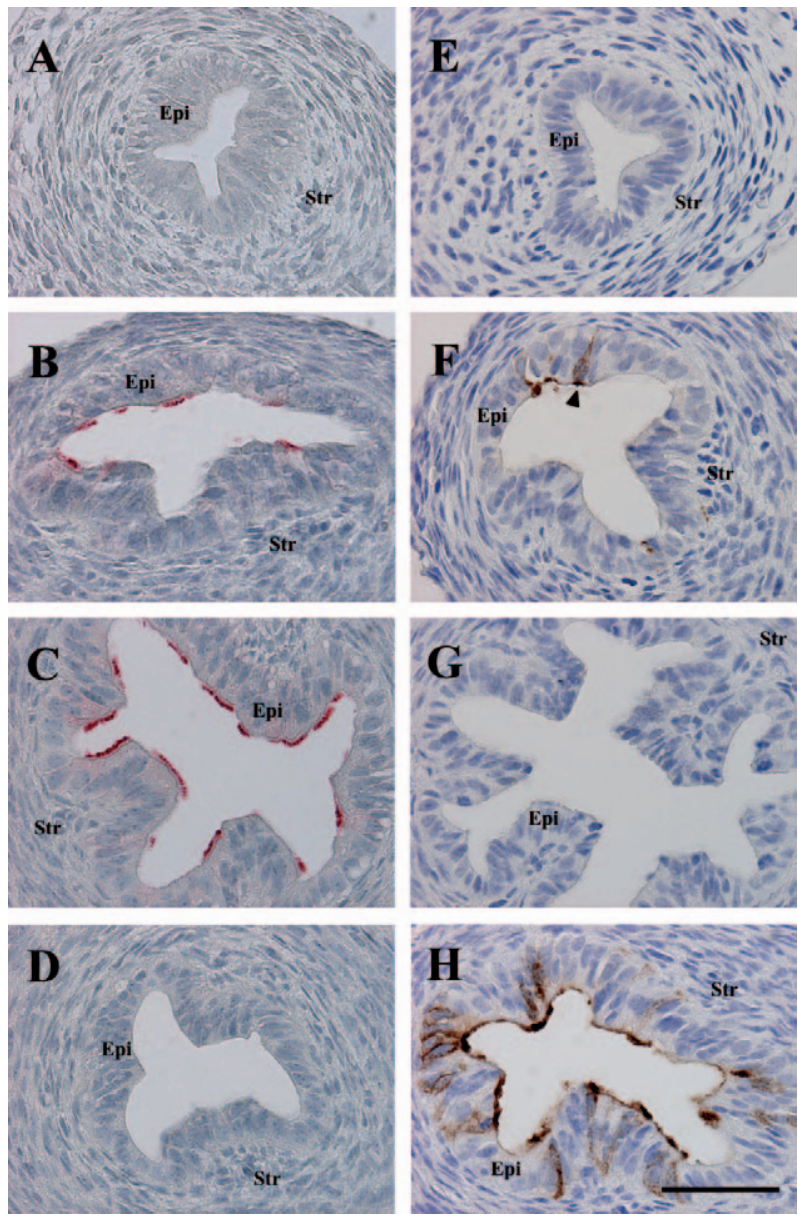

Figure 2 Cytodifferentiation of epithelial cells in the untreated neonatal rat oviduct. Ciliated and secretory epithelial cells were identified by immunohistochemistry for $\beta$-tubulin IV (left panels) and OGP (right panels), respectively, in the untreated neonatal rat oviduct. Epithelial $\beta$-tubulin IV immunoreactivity was negative on ND 5 (A), but was detected on the luminal cell surface on ND 7 (B). On ND 10, $\beta$-tubulin IV was expressed in INF/AMP epithelium (C), but not in IST/UTJ cells (D). Similarly, the presence of OGP was negative on ND 5 (E), but appeared in the cytoplasm of some epithelial cells on ND 7 (arrowhead in F). In contrast to $\beta$-tubulin IV, epithelial OGP was expressed in the IST/UTJ (H), but not in the INF/AMP (G). Epi, epithelium; Str, stroma. Bar: $50 \mu \mathrm{m}$.

Neonatal effects of E2 on cell proliferation and differentiation of the oviduct

In order to understand the role of E2 on neonatal development of the oviduct, either oil vehicle or $10 \mu \mathrm{g}$ E2 was injected into neonatal rats for 5 days starting at the day of birth. Also, oil vehicle or pure estrogen receptor antagonist ICI was concomitantly injected with $10 \mu \mathrm{g}$ E2. We determined the effect of E2 on cell proliferation and differentiation by the double-immunohistochemical detection of PCNA and $\beta$-tubulin IV or OGP. Following E2 treatment, morphological changes of the primitive 

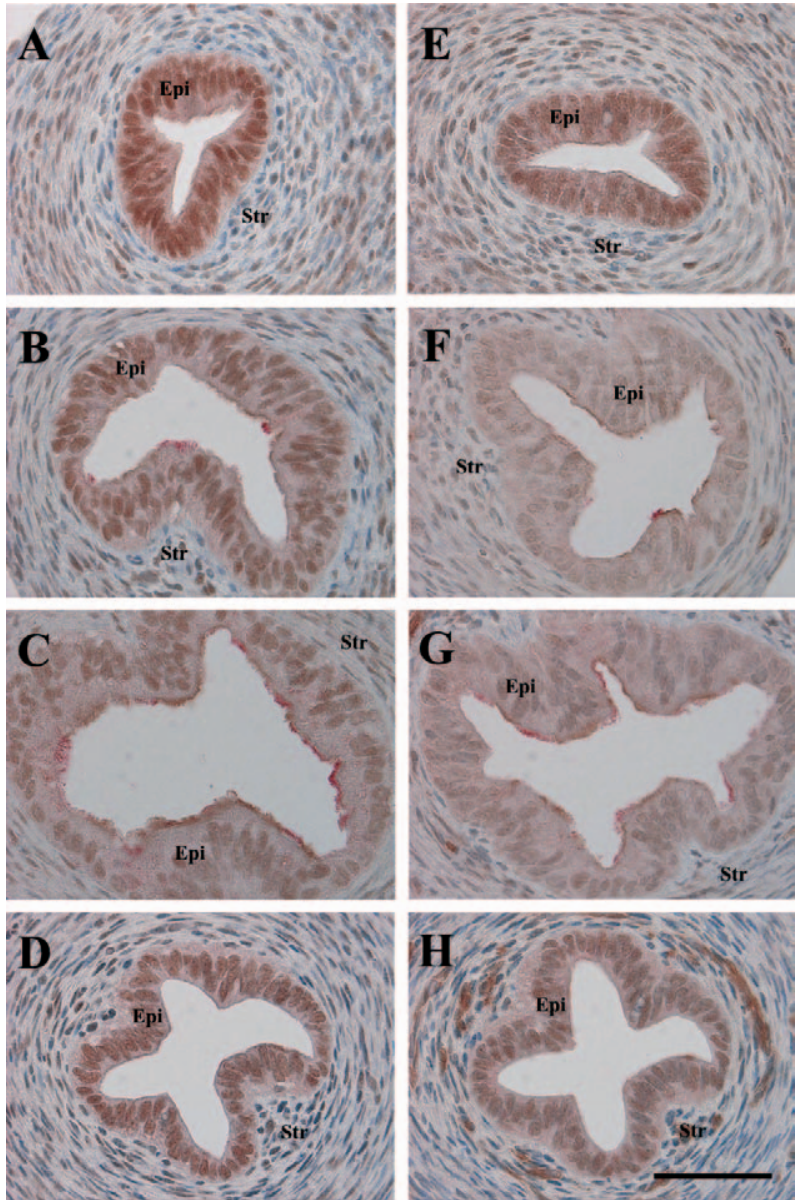

Figure 3 Ontogenic expression of c-jun and c-fos in untreated neonatal mouse oviduct. c-Jun (left panels) and c-fos (right panels) proteins (brown stainings) were evaluated by double immunohistochemistry with $\beta$-tubulin IV (red staining) on ND 5 ( $A$ and $\mathrm{E}$ ), ND 7 (B and F), ND 10 at the INF/AMP region (C and $\mathrm{G})$, and ND 10 at IST/UTJ region (D and H). In the epithelium, nuclear expression of c-jun and c-fos was present on ND 5 ( $\mathrm{A}$ and E), and decreased on ND 7 (B and F). On ND 10, epithelial expression of both proteins was marked in the IST/UTJ (D and H), but diminished in the INF/AMP (C and G). Epi, epithelium; Str, stroma. Bar: $50 \mu \mathrm{m}$.

oviduct tube into the INF/AMP and IST/UTJ was observed on ND 5 when regional differentiation had not occurred in the untreated oviduct. The oviduct exhibited typical estrogen effects such as hypertrophy of the epithelial and stromal cells, including nuclei enlargement, and dilatation of the lumen in the IST/UTJ. In the oil-treated oviduct group, no cells immunopositive for $\beta$-tubulin IV were detected on ND 5 (Fig. 4A). E2 treatment induced epithelial $\beta$-tubulin IV expression on ND 5 only in the INF/AMP region (Figs. 4B and 4C). Treatment with ICI reduced the percentage of $\beta$-tubulin IV-expressing epithelial cells within the duct (Fig. 4D). These observations were in agreement with our previous report (Okada
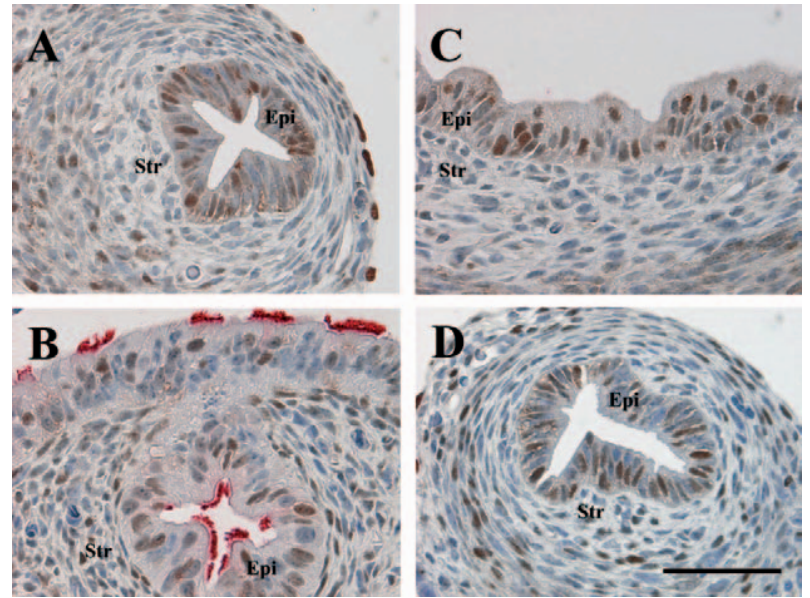

Figure 4 Effects of E2 on epithelial cell proliferation and differentiation as evaluated by PCNA and B-tubulin IV expression in the ND 5 oviduct. Double immunohistochemical staining in the oviduct treated with oil (A), E2 (B and C), and E2 plus ICI (D) was shown. E2 induced $\beta$-tubulin IV (red) expression in epithelial cells of the INF/AMP (B), but not of the IST/UTJ (C). Epithelial PCNA expression was diminished by E2 in the INF/AMP (B), but increased in the IST/UTJ (C). E2 in combination with ICI had no effect on $\beta$-tubulin IV and PCNA expression in the oviduct (D). Epi, epithelium; Str, stroma. Bar: $50 \mu \mathrm{m}$.

et al. 2004). In contrast, in the oil-treated ND 5 oviduct, OGP was not observed and E2-treatment did not induce its expression, even in the epithelial cells of the IST/UTJ.

In the E2-treated tissues on ND 5, epithelial PCNA was observed in more epithelial cells of the IST/UTJ $(36 \cdot 0 \%$, $P<0 \cdot 05$, Fig. 4C) compared with the oil controls $(24 \cdot 2 \%$, Fig. $4 \mathrm{~A})$, but in the INF/AMP $(18.6 \%, P<0 \cdot 05$, Fig.4B), there were fewer PCNA-positive cells encountered than in the oil controls. In the INF/AMP, $\beta$-tubulin IV expression was observed mainly in PCNA-negative cells. Concomitant treatment with ICI retained changes in PCNA made by E2 at the control level (25.6\%, Fig. 4D). These findings, therefore, demonstrate that $\mathrm{E} 2$ induces the differentiation of ciliated epithelial cells after the reduction of their proliferation via ER signaling. However, it does not induce the differentiation of secretory epithelial cells in the ND 5 oviduct in our experiment system.

\section{Neonatal effects of E2 on c-jun and c-fos expression in the oviduct}

To determine the relationship of AP-1 proteins to region and cell type-dependent proliferation and differentiation of epithelial cells after treatment with E2, c-jun and c-fos expression was immunohistochemically evaluated in the oil- or E2-treated rat oviduct. In the oil-treated ND 5 oviduct, c-jun and c-fos proteins were expressed in the epithelium in a pattern similar to those in the untreated ND 5 tissues (Figs. 5A and 5E). Following E2 treatment, 


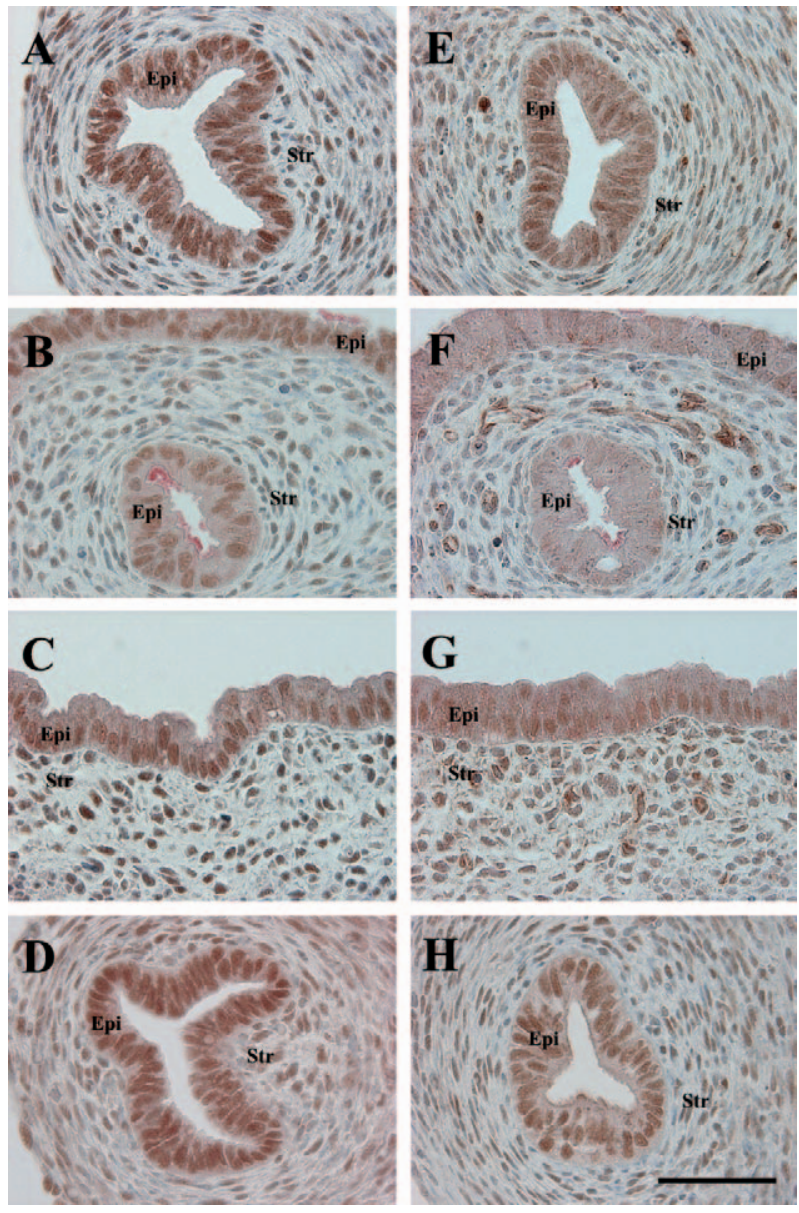

Figure 5 Effects of E2 on expression of c-jun and c-fos in neonatal rat oviduct. Neonatal rats were treated with oil control, E2 or E2 with $\mathrm{ICl}$ and expression of c-jun (left panels, brown staining) or c-fos (right panels, brown staining), and $\beta$-tubulin IV (red staining) in oviduct epithelial cells determined using double

immunohistochemistry. In the oil-treated oviduct, c-jun (A) and $c$-fos $(E)$ were present in the nuclei of epithelial cells throughout the oviduct. Following treatment with $10 \mu \mathrm{g}$ of E2, epithelial $\beta$-tubulin IV expression was induced and both c-jun and c-fos expression was decreased in the INF/AMP (B and F). While no $\beta$-tubulin IV was detected and $\mathrm{c}$-jun and $\mathrm{C}$-fos expression was maintained in the IST/UTJ (C and G). No changes in the expression of c-jun and c-fos were exhibited in the epithelium when treated concomitantly with $\mathrm{E} 2$ and $\mathrm{ICl}(\mathrm{D}$ and $\mathrm{H})$. Epi, epithelium; Str, stroma. Bar: $50 \mu \mathrm{m}$.

epithelial expression of $\mathrm{c}$-jun and c-fos were reduced specifically in the INF/AMP region (Table 1, Figs. 5B and $5 \mathrm{~F}$ ), but unchanged in the IST/UTJ region (Table 1, Figs. 5C and 5G). Concomitant treatment with ICI retained the E2 effects at levels comparable to the oiltreated control (Figs. 5D and 5H). Thus E2 reduces c-jun and $\mathrm{c}-\mathrm{fos}$ proteins in association with the promotion of ciliated epithelial cell differentiation in the INF/AMP. While, in the IST/UTJ, epithelial cells proliferated, but
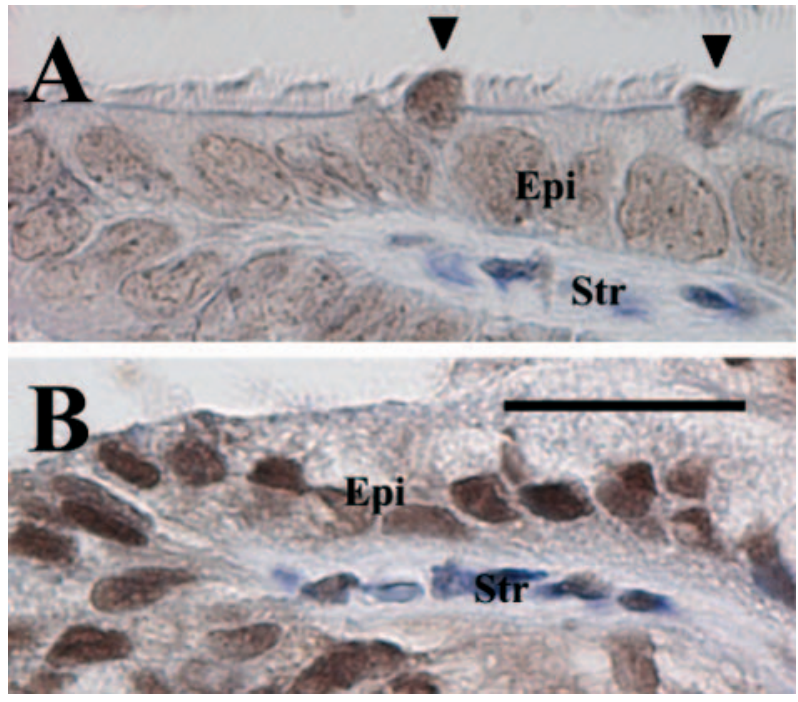

Figure 6 Effect of foxj 1 on the expression of c-jun in oviduct epithelial cells. Expression of c-jun was evaluated by immunohistochemistry in wild-type (A) and foxj1-null (B) oviduct. Epithelial cells in the AMP of the wild-type oviduct showed marked c-jun expression in nonciliated cells (arrowheads), but less expression in ciliated cells. In contrast, in the foxj1-null oviduct, c-jun protein was highly expressed in all epithelial cells (all nonciliated cells). Epi, epithelium; Str, stroma. Bar: $20 \mu \mathrm{m}$.

they did not differentiate into secretory cells when AP-1 proteins were expressed.

Expression of epithelial c-jun in the oviduct of the foxj1-deficient mice

In order to understand the relationship between the differentiation and the $c$-jun reduction in ciliated epithelial cells, the expression of c-jun was evaluated in oviducts from 3-week-old mice genetically deficient in foxj1. The foxj1-null oviduct lacks the differentiation of ciliated cells and exhibits the nonciliated phenotype in all epithelial cells (Chen et al. 1998, Brody et al. 2000). In the wild-type mouse oviduct, $\beta$-tubulin IV and foxj1 were expressed in ciliated epithelial cells, but not in the foxj1-null oviduct (data not shown, Okada et al. 2004). Expression of c-jun was detected in only nonciliated epithelial cells (arrowheads) of the ampulla (AMP) region where the protein was down-regulated in ciliated cells of the wild-type oviduct (Fig. 6A). Interestingly, in the foxj1-null oviduct, the persistent expression of $\mathrm{c}$-jun was exhibited in all AMP epithelial cells (Fig. 6B). Thus foxj1-inducing ciliogenesis is required for the reduction of $\mathrm{c}$-jun in oviduct differentiation.

\section{Discussion}

E2 induces epithelial cell proliferation with the increased expression of AP-1 transcription factors in the rat and 
mouse uterus (Loose-Mitchell et al. 1988, Weisz \& Bresciani 1988, Weisz et al. 1990, Webb et al. 1990, 1993, Chiappetta et al. 1992, Kamiya et al. 1996). In the chick oviduct, however, AP-1 transcription factors are reduced following E2 treatment and induced by an antiestrogen tamoxifen (Cohrs et al. 1988, Lau et al. 1990, 1991). It has been speculated that the reduction of AP-1 transcription factors in the chick oviduct are related to the differentiation of secretory epithelial cells since it accompanies the elevation of ovalbumin expression. In this study, in order to determine the relationship between AP-1 transcription factor expression, cell proliferation, and differentiation, we used neonatal rat oviducts which had been treated with E2 for 5 days starting at the day of birth. The results showed that cell proliferation and ciliated cell differentiation occurred in specific oviduct regions (Okada et al. 2004). We evaluated the effect of E2 on the expression of $\mathrm{c}$-jun and $\mathrm{c}$-fos mRNAs in the whole oviduct, including all regions. We found, after E2 treatment on ND 5, that expression of these AP-1 mRNAs did not change (not shown). In the immunohistochemical study, however, the region- and cell type-dependent change in their proteins was exhibited in the ND 5 rat oviduct treated with E2. Additionally, following E2 treatment, epithelial cell proliferation was induced along with higher expression of $\mathrm{c}$-jun and $\mathrm{c}$-fos in the IST/UTJ region, whereas in the INF/AMP region, ciliated epithelial cell differentiation was induced concurrently with reduced expression of $\mathrm{c}$-jun and $\mathrm{c}$-fos. Thus, early in differentiation, the role of AP-1 induction by E2 is likely to be similar to that in the uterus, suggesting that $\mathrm{c}-\mathrm{jun}$ and c-fos have a regulatory role in cell proliferation in the oviduct epithelium. However, after cell proliferation, the subsequent AP-1 reduction suggests a regulated stage of transition and maturation for the ciliated epithelial cells. Changes caused by E2 were diminished by concomitant treatment with a pure ER antagonist ICI, indicating that E2 acts throughout ER signaling. In the neonatal rat oviduct, $\operatorname{ER} \alpha$ was expressed in all epithelial cells, but $\operatorname{ER} \beta$ was not even after E2 treatment (Yamashita et al. 1989, Okada et al. 2003). These findings suggest that the main target receptor of E2 in the neonatal rat oviduct is ER $\alpha$. Taken together, transcription of AP-1 transcription factors are increased by an E2-ER $\alpha$ complex via ERE in the primary proliferation phase, and decreased with transition to the secondary differentiation phase. Our previous study indicates that epithelial $\operatorname{ER} \alpha$ in the neonatal rat oviduct disappears during differentiation to ciliated cells which results in the loss of responsiveness to E2-inducing AP-1 expression via ERE.

The molecular mechanism of the transition of proliferation to differentiation is unknown. However, foxj1 is a key transcription factor for differentiation to ciliated epithelial cells. The ciliated epithelial cells of foxj1deficient mice lack differentiation (Chen et al. 1998, Brody et al. 2000). Moreover, in the oviduct, foxj1 expression was detected at ND 0, prior to the appearance of cilia in epithelial cells. This expression was induced by $\mathrm{E} 2$ in the epithelial cells of the INF/AMP region upon the appearance of ciliated cells (Okada et al. 2004). The persistent expression of $\mathrm{c}-\mathrm{jun}$ in all epithelial cells (nonciliated cells) in the foxj1-null oviduct suggests that foxj1 induction of ciliated cell differentiation is required for the reduction of epithelial $c$-jun at the INF/AMP. This concept supports previous findings which reported mutually exclusive expression of foxj1 and the cell proliferation marker bromo-deoxyuridine in the lung (Look et al. 2001). In contrast, although secretory epithelial cells were not found to be induced in this study, the expression of AP-1 proteins and ER $\alpha$ in secretory (nonciliated) epithelial cells of the mature rat oviduct have been reportedly maintained (Mowa \& Iwanaga 2000, Okada et al. 2003). The activation of ovalbumin gene expression by the ER/c-jun/c-fos complex (Gaub et al. 1990) supports the concept that AP-1 proteins and ER may be essential for secretory cell function. For example, in the epithelium of the vas deferens, androgen increases AP-1 activity prior to cell proliferation and decreases it when differentiation occurs (Darne et al. 2000). Taken together, AP-1 transcription factors play an important role in sex steroid hormone-regulated proliferation, differentiation, and function of the epithelium in male and female reproductive organs.

In summary, this study suggests that AP-1 transcription factors direct proliferation, differentiation, and function of the epithelial cells in a region- and cell-dependent manner. This study serves as a fundamental tool to enable the understanding of the molecular and cellular mechanisms of epithelial cell differentiation and proliferation of the neonatal rat oviduct. Based on this and our previous studies, we hypothesize that in early neonatal development, the initiation of E2 production and the concomitant increase in oviductal ER $\alpha$ expression (Okada et al. 2003) induce foxj1 expression in the programmed ciliated cells of the INF/AMP with a loss of $\operatorname{ER} \alpha$ and a subsequent reduction of AP-1 transcription factors which sequentially promote epithelial ciliogenesis (Okada et al. 2004). However, although the stimulation of ER signaling accelerates the differentiation process of ciliated epithelial cells, we suggested that it is not fundamentally required for this event because of the presence of cilia in the ER $\alpha$-deficient oviduct (Okada et al. 2004). Also, it should be considered that the expression level of epithelial c-fos and c-jun, and their subsequent responsiveness to E2 were altered in the uterus of mice treated neonatally with $4 \mu \mathrm{g}$ DES for 5 days, starting at birth (Yamashita et al. 2001, 2003). Thus our system using neonatal rats treated with $10 \mu \mathrm{g}$ of E2 could possibly represent a pharmacological condition rather than a physiological one. Further evaluation of the relationship between regulatory proteins in the oviduct is required to elucidate these mechanisms physiologically. 


\section{Acknowledgements}

The authors gratefully acknowledge Emeritus Professor Noboru Takasugi for critical reading of the manuscript.

\section{Funding}

This work was supported in part by a Grant-in-Aid for Scientific Research on Priority Areas (A) from the Ministry of Education, Culture, Sports, Science, and Technology of Japan, the Environmental Research Grant from the Ministry of Environment, and the Health Sciences Research Grant from the Ministry of Health, Labor, and Welfare, Japan.

\section{References}

Abe H \& Abe M 1993 Immunological detection of an oviductal glycoprotein in the rat. Journal of Experimental Zoology 266 328-335.

Abe H \& Oikawa T 1993 Effects of estradiol and progesterone on the cytodifferentiation of epithelial cells in the oviduct of the newborn golden hamster. Anatomical Record 235 390-398.

Anderson RGW \& Hein CE 1976 Estrogen dependent ciliogenesis in the chick oviduct. Cell and Tissue Research 171 459-466.

Angel P \& Karin M 1991 The role of Jun, Fos and the AP-1 complex in cell-proliferation and transformation. Biochimica et Biophysica Acta 1072 129-157.

Bannerjee A, Roach MC, Trcka P \& Luduena RF 1992 Preparation of a monoclonal antibody specific for the class IV isotype of $\beta$-tubulin. Purification and assembly of $\alpha \beta_{\text {II }}, \alpha \beta_{\text {III }}$ and $\alpha \beta_{\text {IV }}$ tubulin dimers from bovine brain. Journal of Biological Chemistry 267 5625-5630.

Bigsby RM \& Li A 1994 Differentially regulated immediate early genes in the rat uterus. Endocrinology 134 1820-1826.

Brody SL, Yan XH, Wuerffel MK, Song SK \& Shapiro SD 2000 Ciliogenesis and left-right axis defects in forkhead factor HFH-4-null mice. American Journal of Respiratory Cell and Molecular Biology 23 45-51.

Chen J, Knowles HJ, Hebert JL \& Hackett BP 1998 Mutation of the mouse hepatocyte nuclear factor/forkhead homologue 4 gene results in an absence of cilia and random left-right asymmetry. Journal of Clinical Investigation 102 1077-1082.

Chiappetta C, Kirkland JL, Loose-Mitchell DS, Murthy L \& Stancel GM 1992 Estrogen regulates expression of the jun family of protooncogenes in the uterus. Journal of Steroid Biochemistry and Molecular Biology 41 113-123.

Cohrs RJ, Goswami BB \& Sharma OK 1988 Down regulation of c-myc, c-fos and erb-B during estrogen induced proliferation of the chick oviduct. Biochemical and Biophysical Research 150 82-88.

Darne C, Martinez A, Lallemand D, Morel L, Jean Cl, Saru JP, Schmid HP \& Manin M 2000 Down-regulation of AP1 activities after polarization of vas deferens epithelial cells correlates with androgen-induced gene expression. Journal of Steroid Biochemistry and Molecular Biology 72 103-113.

Eroschenko VP 1982 Surface changes in oviduct, uterus and vaginal cells of neonatal mice after estradiol- $17 \beta$ and the insecticide chlordecone (Kepone) treatment: a scanning electron microscopic study. Biology of 26 707-720.

Gaub MP, Bellard M, Scheuer I, Chambon P \& Sassone-Corsi P 1990 Activation of the ovalbumin gene by the estrogen receptor involves the fos-jun complex. Cell $\mathbf{6 3} 1267-1276$.
Hyder SM, Stancel GM, Nawaz Z, McDonnell DP \& Loose-Mitchell DS 1992 Identification of an estrogen response element in the $3^{\prime}$-flanking region of the murine c-fos protooncogene. Journal of Biological Chemistry 267 18047-18054.

Hyder SM, Nawaz Z, Chiappetta C, Yokoyama K \& Stancel GM 1995 The protooncogene c-jun contains an unusual estrogen-inducible enhancer within the coding sequence. Journal of Biological Chemistry 270 8506-8513.

Jansen RPS 1984 Endocrine response in the fallopian tube. Endocrine Reviews 5 525-551.

Kamiya K, Sato T, Nishimura N, Goto Y, Kano K \& Iguchi T 1996 Expression of estrogen receptor and proto-oncogene messenger ribonucleic acids in reproductive tracts of neonatally diethylstilbestrol-exposed female mice with or without postpuberal estrogen administration. Experimental and Clinical Endocrinology and Diabetes 104 111-122.

Lau CK, Subramaniam M, Rasmussen K \& Spelsberg TC 1990 Rapid inhibition of the c-jun proto-oncogene expression in avian oviduct by estrogen. Endocrinology 127 2595-2597.

Lau CK, Subramaniam M, Rasmussen K \& Spelsberg TC 1991 Rapid induction of the c-jun protooncogene in the avian oviduct by the antiestrogen tmoxifen. Proceedings of the National Academy of Science of the United States of America 88 829-833.

Look DC, Walter MJ, Williamson MR, Pang L, You Y, Sreshta JN, Johnson JE, Zander DS \& Brody SL 2001 Effects of paramyxoviral infection on airway epithelial cell foxj1 expression, ciliogenesis, and mucociliary function. American Journal of Pathology $\mathbf{1 5 9}$ 2055-2069.

Loose-Mitchell DS, Chiappetta C \& Stancel GM 1988 Estrogen regulation of c-fos messenger ribonucleic acid. Molecular Endocrinology 2 946-951.

Mangelsdorf DJ, Thummel C, Beato M, Herrlich P, Schütz G, Umesono K, Blumberg B, Kastner P, Mark M, Chambon P \& Evans RM 1995 The nuclear receptor superfamily: the second decade. Cell 83 835-839.

Mendoza-Rodrí guez CA, Merchant-Larios H, Segura-Valdez ML, Moreno-Mendoza N, Cruz ME, Arteaga-López P, Camacho-Arroyo I, Domí nguez R \& Cerbón M 2003 c-fos and estrogen receptor gene expression pattern in the rat uterine epithelium during the estrous cycle. Molecular Reproduction and Development 64 379-388.

Mowa CN \& Iwanaga T 2000 Developmental changes of the oestrogen receptor- $\alpha$ and $-\beta$ mRNAs in the female reproductive organ of the rat-analysis by in situ hybridization. Journal of Endocrinology 167 363-369.

Newbold RR, Bullock BC \& McLachlan JA 1983 Exposure to diethylstilbestrol during pregnancy permanently alters the ovary and oviduct. Biology of Reproduction 28 735-744.

Okada A, Sato T, Ohta Y, Buchanan DL \& Iguchi T 2001 Effect of diethylstilbestrol on cell proliferation and expression of epidermal growth factor in the developing female rat reproductive tract. Journal of Endocrinology 170 539-554.

Okada A, Ohta Y, Inoue S, Hiroi H, Muramatsu M \& Iguchi T 2003 Expression of estrogen, progesterone and androgen receptors in the oviduct of developing, cycling and pre-implantation rats. Journal of Molecular Endocrinology 30 301-315.

Okada A, Ohta Y, Brody SL, Watanabe H, Krust A, Chambon P \& Iguchi T 2004 Role of foxj1 and estrogen receptor alpha in ciliated epithelial cell differentiation of the neonatal oviduct. Journal of Molecular Endocrinology 32 615-625.

Rauscher FJ III, Sambucetti LC, Curran T, Distel RJ \& Spiegelman BM 1988 Common DNA binding site for fos protein complexes and transcription factor AP-1. Cell 52 471-480.

Renthal R, Schneider BG, Miller MM \& Ludueña RF $1993 \beta_{\text {IV }}$ is the major $\beta$-tubulin isotype in bovine cilia. Cell Motility and the Cytoskeleton 25 19-29. 
Schuchard M, Landers JP, Sandhu NP \& Spelsberg TC 1993 Steroid hormone regulation of nuclear proto-oncogenes. Endocrine Reviews 14 659-669.

Webb DK, Moulton BC \& Khan SA 1990 Estrogen induced expression of the c-jun proto-oncogene in the immature and mature rat uterus. Biochemical and Biophysical Research Communications $168721-726$.

Webb DK, Moulton BC \& Khan SA 1993 Estrogen induces expression of $\mathrm{c}-j u n$ and $j u n-\mathrm{B}$ protooncogenes in specific rat uterine cells. Endocrinology 133 20-28.

Weisz A \& Bresciani F 1988 Estrogen induces expression of c-fos and c-myc protooncogenes in rat uterus. Molecular Endocrinology 2 816-824.

Weisz A \& Rosales R 1990 Identification of an estrogen response element upstream of the human c-fos gene that bind the estrogen receptor and the AP-1 transcription factor. Nucleic Acids Research 18 5097-5106.

Weisz A \& Bresciani F 1993 Estrogen regulation of proto-oncogenes coding for nuclear proteins. Critical Reviews in Oncogenesis 4 361-388.
Weisz A, Cicatiello L, Persico E, Scalona M \& Bresciani F 1990 Estrogen stimulates transcription of c-jun protooncogene. Molecular Endocrinology 4 1041-1050.

Yamashita S, Newbold RR, McLachlan JA \& Korach KS 1989 Developmental pattern of estrogen receptor expression in female mouse genital tracts. Endocrinology 125 2888-2896.

Yamashita S, Takayanagi A \& Shimizu N 2001 Effects of neonatal diethylstilbestrol exposure on $\mathrm{c}$-fos and $\mathrm{c}$-jun protooncogene expression in the mouse uterus. Histology and Histopathology 16 131-140.

Yamashita S, Takayanagi A \& Shimizu N 2003 Expression of c-fos and c-jun protooncogenes in the uteri of immature mice neonatally exposed to diethylstilbestrol. Histology and Histopathology 18 83-92.

Received 8 April 2004

Accepted 1 June 2004

Made available online as an

Accepted Preprint 7 June 2004 